\title{
Cytological, Bacteriological and Antibiogram Studies for the Management of Uterine Infection in Repeat Breeder Bovines
}

Megha Pande, Suresh Kumar, Y.K. Soni, N. Prasad, N. Chand, S. Saha, Sarika, S. Arya, S. Tyagi

10.18805/IJAR.B-4776

\begin{abstract}
Background: Repeat breeding syndrome (RBS) associated with sub-clinical uterine infection (UI) remains to be a major reproductive problem faced by Indian farmers. Present study documents its diagnosis, prevalent etiological agents, antibiogram pattern and efficacy of the treatment at field level.

Methods: Seventy-eight RBS affected bovines were selected. The cervical mucous (CM) was collected for study of its characteristics, white-side test, endometrial cytology, microbial examination and antibiogram. The treatment protocol was developed and the animals response to the treatment was assessed.

Result: The overall incidence of RBS was found to be $12.9 \%$ and the cases associated with uterine infection (RBS/UI+ve) and without uterine infection (RBS/UI-ve) were $44.87 \%$ and $55.13 \%$, respectively. The mean scores of $\mathrm{CM}$ character, odour, $\mathrm{pH}$ and number of polymorphonuclear cells in RBS/UI +ve were $2.09 \pm 1.39,1.14 \pm 0.12,8.49 \pm 0.08$ and $12.46 \pm 0.96$, respectively, and differed significantly $(\mathrm{P}<0.05)$ from RBS/UI-ve cases. The microbial examination revealed the presence of gram negative bacilli, Trueperella spp., Pseudomonas spp., Staphylococcus spp., Escherichia coli and yeast infection. Antibiogram studies recorded the response of Tetracyclin as best $(48.57 \%)$ followed by Cephalexin $(22.86 \%)$, Chloramphenicol $(20.0 \%)$ and Streptomycin $(8.57 \%)$. The RBS/UI+ve cases were treated individually, on one-to-one basis, obeying antibiogram. The infection appeared to be considerably controlled and overall success rate was observed in the form of confirmed pregnancy in $71.43 \%$ cases. Thus, it was concluded that prompt diagnosis using endometrial cytology and antibiogram guided therapeutic approach may aid for effective management of RBS/UI +ve cases, under field conditions.
\end{abstract}

Key words: Antibiogram, Endometrial cytology, Repeat breeding, Uterine infection.

\section{INTRODUCTION}

Repeat breeding syndrome (RBS) is responsible for huge economic losses to dairy farmers in India under field conditions. A "repeat breeder" cow has been typically welldefined as any cow that has normal or near to normal oestrous cycle length but fails to conceive following three or more than three successive services, and on examination there are no obvious evident abnormalities. Although predisposition of RBS is multi-factorial, infection in the uterine environment is considered to be one of the significant cause which adversely affects the reproductive performance of dairy animals (Rangnekar et al., 2005).

Usually in bovines, the uterine health is often compromised following difficult parturition or dystocia. Obstetrical manoeuvres wherein the foetus is removed following prolonged traction or the cases associated with twinning or abnormal birth, induced calving, cervico-vaginal or uterine prolapse, retention of foetal membranes etc. make the uterus more vulnerable for infection. Absence of proper aseptic measures during artificial insemination, dirty animalsheds and unclean animals may also make them prone to catch uterine diseases. Uterine infections may be either limited to only mucosal layer (endometritis) or could extend to deep muscular layers (metritis) and also there may be a gradual accretion of purulent discharge in the uterus (pyometra). Any such infection, according to the degree of
Division of Cattle Physiology and Reproduction, ICAR-Central Institute for Research on Cattle, Meerut-250 001, Uttar Pradesh, India.

Corresponding Author: Megha Pande, Division of Cattle Physiology and Reproduction, ICAR-Central Institute for Research on Cattle, Meerut-250 001, Uttar Pradesh, India.

Email: megha.pande@icar.gov.in

How to cite this article: Pande, M., Kumar, S., Soni, Y.K., Prasad, N., Chand, N., Saha, S., Sarika, Arya, S. and Tyagi, S. (2022). Cytological, Bacteriological and Antibiogram Studies for the Management of Uterine Infection in Repeat Breeder Bovines. Indian Journal of Animal Research. DOI: 10.18805/IJAR.B-4776.

Submitted: 15-09-2021 Accepted: 16-12-2021 Online: 14-01-2022

severity, distresses the reproductive efficiency of dairy animals and are associated with poor fertility.

Under field conditions, we were encountering cases of RBS, which were typically found in pluriparous cattle and buffaloes. It was observed that following calving, the animal showed oestrus signs at regular intervals, however failed to conceive repeatedly. The animals were given mineral supplements and fertility boosters, however, they did not respond well. As, there was no preliminary data and studies related to repeat breeders in the said area, the present study was intended to diagnose the cause, to isolate the prevalent 
Cytological, Bacteriological and Antibiogram Studies for the Management of Uterine Infection in Repeat Breeder Bovines

etiological agents, to determine the antibiogram pattern and to assess the efficacy of treatment to eliminate the infection and restore the fertility in dairy animals.

\section{MATERIALS AND METHODS Experimental animals}

The study was conducted during 2018-19, in the villages of western Uttar Pradesh, adopted under Farmer-FIRST programme of ICAR-Central Institute for Research on Cattle, Meerut. The animals were presented during the various health camps organised in the adopted villages. Apparently, the RBS affected animals appeared to have no physical or physiological abnormality, so, the owners were advised to present the animal for examination, on the day of oestrus. The bovines ( $n=78$; 33 cows and 45 buffaloes) which had RBS were selected.

\section{Cervical mucus characteristics}

Following proper restraint, the perineal region was cleaned and sanitized. Per-rectally, bovine genitalia was massaged and cervical mucus was collected in sterilized glass tubes. Grossly, it was checked for consistency and presence of pus flakes, odour and abnormal discharge, if any. The mucous character and the vaginal mucous odour were recorded as per Sheldon et al. (2006).

\section{White side test}

Briefly, the endometrial fluid/mucous was aseptically collected and mixed with equal volume of $5 \% \mathrm{NaOH}$. The mixture was then heated up to the boiling point and the intensity of colour changed was studied and graded accordingly.

\section{Endometrial cytology}

The sample was aseptically collected using a cytobrush. The smears were fixed using absolute methanol for 10 minutes and stained with Giemsadye (HiMedia). Cytological assessment was done by determining the percent PMNs cells (Gilbert et al., 2005).

\section{Microbial examination of cervical mucous}

The aseptically collected samples were enriched in MullerHinton broth and thereafter streaked onto the nutrient agar plates. The isolated colonies of the microorganisms were again plated onto specific media plates as pure culture and growth characteristics of the isolates and result of Gram stain were recorded, which was further confirmed by biochemical tests.

\section{Antibiotic sensitivity test}

The in vitro antibiotic sensitivity tests were carried out by disc diffusion technique as per the manufacturers. Briefly, two plates were employed for each sample. The first plate contained separate discs (HiMedia) containing Ampicillin 10 $\mu \mathrm{g}$, Chloramphenicol $25 \mu \mathrm{g}$, Penicillin G $1 \mathrm{U}$, Streptomycin $10 \mu \mathrm{g}$, Sulphatriad $300 \mu \mathrm{g}$ and Tetracyclin $25 \mu \mathrm{g}$ per disc. The second plate for the same sample contained Gentamicin $10 \mu \mathrm{g}$, chloramphenicol $30 \mu \mathrm{g}$, Cephalexin $30 \mu \mathrm{g}$, Cefepime $30 \mu \mathrm{g}$ and co-trimoxazole $25 \mu \mathrm{g}$.

\section{Treatment protocol}

After the results of the antibiogram were available, the most effective antibiotic as per the individuals' result was prescribed parenterally as well as infused via intrauterine route. The treatment was started when the animal was in period of oestrous, and was continued for 5 days. Besides, the animals, where the score of cervical secretions was between 2 to 3 and obvious inflammation was present, Flunixin meglumine @ $2.2 \mathrm{mg} / \mathrm{kg}$ Body weight, IM, was given once a day for 3 days.

\section{Assessment of response to the treatment}

The clinical response was assessed by examining gross cervical mucus characteristics, endometrial cytology and white-side test on subsequent oestrus. If no abnormality was found, the animals were inseminated twice, $12 \mathrm{~h}$ apart, following am-pm rule. Pregnancy was confirmed by rectal palpation at 60 days following insemination. Data were analysed as per Snedecor and Cochran (1994).

\section{RESULTS AND DISCUSSION}

Based on our observations, the overall incidence of RBS was $12.9 \%$ in the villages of Meerut District. In different places, incidences have been reported to vary from 1 to $30 \%$, under farm and field conditions (Bhat et al., 2012; Saraswat and Purohit, 2016; Asaduzzaman et al., 2016). Out of 78 RBS cases presented, the cases that were associated with and without uterine infection were $44.87 \%$ $(35 / 78)$ and $55.13 \%(43 / 78)$, respectively. The infection
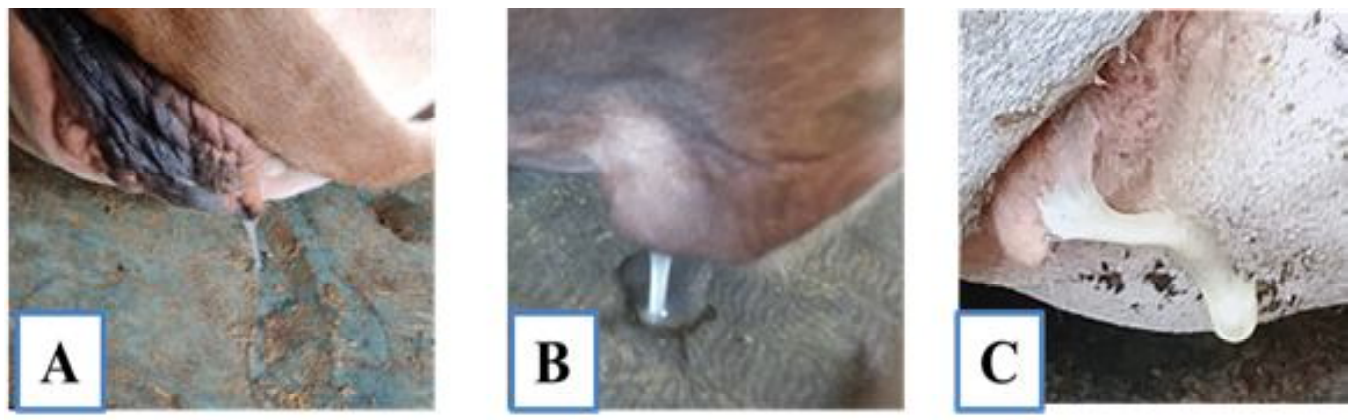

Fig 1: Cervical mucous released at oestrous in bovines suffering from uterine infection associated repeat breeding syndrome. Photographs A, B and C depicts mucous character score of 01,02 and 03 , respectively. 
ranged from low grade to detectable type in sub-clinical and clinical form as $29.49 \%$ and $15.38 \%$, respectively.

Thus, the study showed that primarily nearly 40 to $50 \%$ of the repeat breeder animals suffered from uterine infection. However, most of the owners remain ignorant towards the infectious secretions and repeatedly complain of poor fertility, without knowing the actual cause. This may be due to the reason that, all the cows that were presented had normal feeding behaviour and usual cyclicity. Noakes et al. (2001) have also described subclinical uterine infection as the primary cause of RBS in bovines. It may cause direct endometrial damage or may affect conception by producing toxins. It is also known to have an inhibitory effect on growth of the largest follicle (Heidari et al., 2016) which in turn may lead to impaired corpus luteum development and function (Pande et al., 2013). Various other reports also suggest that improved uterine health helps in better conception rates and reduces RBS in bovines (Kumar et al., 2013; Singh et al., 2017).

\section{Cervical mucus characteristics, white-side test and endometrial cytology}

The nature and type of mucus and cervical secretions were categorized to produce a clinical score for differentiating the samples (Fig 1).

The mean score of the mucous character, odour, $\mathrm{pH}$ and number of PMN cells in RBS cases associated with and without uterine infection, is presented in Table 1. The cases where uterine infection was associated with RBS, the cows had either mucoid discharge with flecks of pus or discharge containing less than $50 \%$ white and yellowish white pus, whereas in other RBS cases, the cervico-vaginal mucous was clear and translucent. Similar trend was found with odour score (Table 1). The overall mean $\mathrm{pH}$ of infected sample was more than 8 in 25 animals (69.45\%) in uterine infection positive RBS cases. The white side test came to be positive in 28 animals out of 35 animals (77.14\%).

The final diagnosis was based on endometrial cytology, wherein a higher proportion of samples were diagnosed as positive for infection (35 out of 78 samples, 44.87\%). Very few or no PMN cells were observed in other RBS associated cases $(55.13 \%)$. The number of PMN cells was significantly higher $(P<0.001)$ in the uterine infection positive RBS cases (Table 1, Fig 2).

Uterine infection associated with RBS is difficult to diagnose under field conditions in normal cyclic cows. Examination of cervical mucous may not always lead to a confirmed diagnosis. However, the present study suggests that if a case is presented as a RBS, the owner should be asked to bring the animal for examination only when it is in oestrus. White side test on cervical mucus would be helpful in diagnosis under field conditions, however it may not be full proof. Endometrial cytology will be the best technique to be employed for confirmation. It is easy, quick, inexpensive and gives reliable results. Earlier reports suggest that white side test and endometrial cytology (Bhat et al., 2014; Dutt et al., 2017) both may aid in diagnosing sub-clinical uterine infection.

\section{Microbial examination of cervical mucous}

The bacteriological investigation of the samples revealed the presence of several bacterial species. Gram negative bacilli were the most common isolate found in the uterus (45\%). Other isolates were Trueperella spp., Pseudomonas spp., Staphylococcus spp. and Escherichia coli (Fig 3). Mixed infections were found in $27.48 \%$ cases. One animal was also found to be infected with yeast (Fig 3). E. coli, Staphylococcus, Trueperella, Bacillus spp. etc. have also been commonly found, identified and recorded in the past studies in repeat breeders (Gani et al., 2008; Dutt et al., 2017).

Table 1: Means \pm SEM of different tests performed on bovines suffering from repeat breeding syndrome (RBS) associated with (+ve) and without (-ve) uterine infection.

\begin{tabular}{lcccc}
\hline Total RBS cases & MCS & Odour score & pH & PMN cells \\
\hline Uterine infection +ve $(n=35)$ & $2.09 \pm 1.39^{\mathrm{a}}$ & $1.14 \pm 0.12^{\mathrm{a}}$ & $8.49 \pm 0.08^{\mathrm{a}}$ & $12.46 \pm 0.96^{\mathrm{a}}$ \\
Uterine infection --ve $(\mathrm{n}=43)$ & $0.00^{\mathrm{b}}$ & $0.00^{\mathrm{b}}$ & $6.61 \pm 0.06^{\mathrm{b}}$ & $2.67 \pm 0.52^{\mathrm{b}}$ \\
\hline
\end{tabular}

MCS: Mucous character score; OS: Odour score; PMN: Polymorphonuclear cells;

a,b Values bearing different superscripts in a column differ significantly $(P<0.05)$.

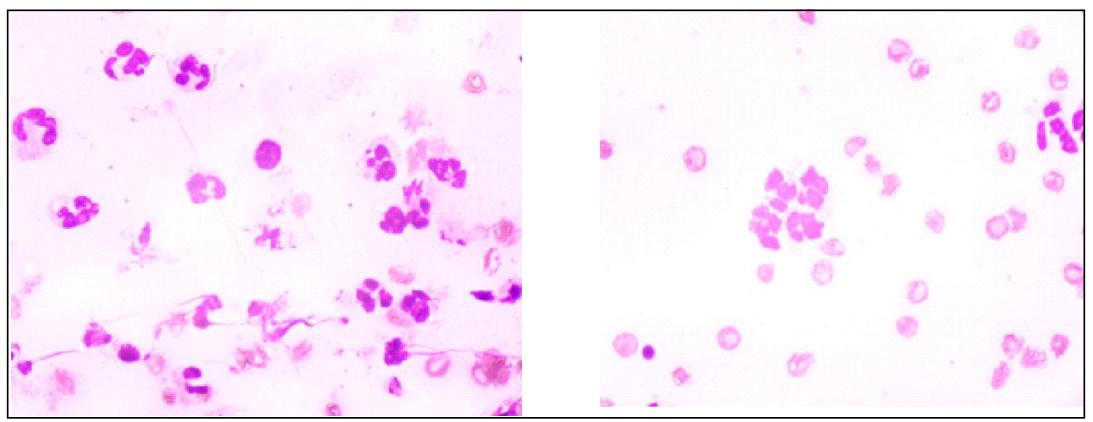

Fig 2: Endometrial cytology of bovines suffering from uterine infection associated repeat breeding syndrome. Slide shows high infiltration of PMN cells $(400 \times)$. 


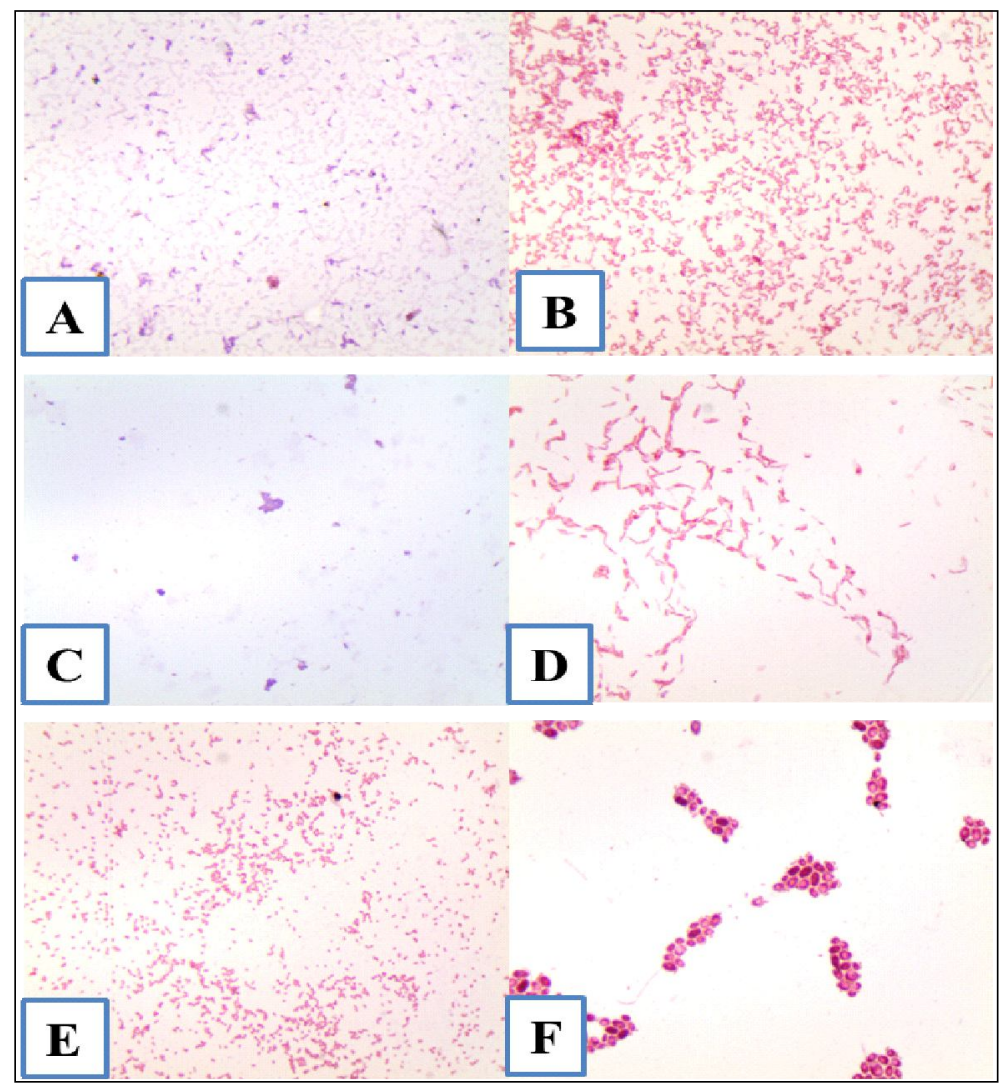

Fig 3: Gram stain of uterine culture, showing A) Trueperella spp. B) Pseudomonas spp. C) Staphylococcus spp. D) gram negative bacilli E) E. coli and F) Yeast.

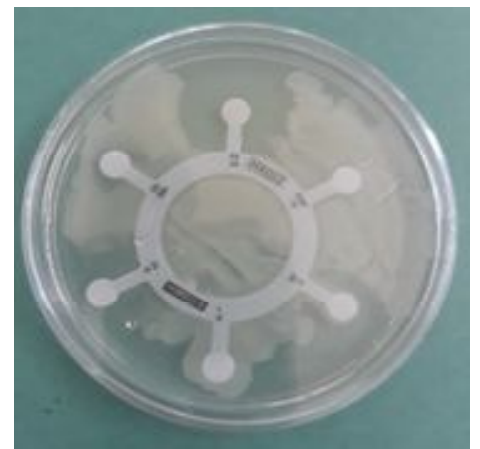

Fig 4: Antibiogram of uterine infection positive animal.

However, there are scanty reports which have described the role of yeast in bovine infertility (Saini et al., 2019).

\section{Antibiotic sensitivity test}

The antibiogram of all positive animals varied greatly in terms of zone of inhibition. According to result, the response for Tetracyclin (Fig 4) was found to be best in maximum number of infected cases $(17 / 35 ; 48.57 \%)$ followed by Cephalexin $(8 / 35 ; 22.86 \%)$, Chloramphenicol $(7 / 35 ; 20.0 \%)$, Streptomycin $(3 / 35 ; 8.57 \%)$. Clear zone of inhibition was either absent or had irregular boundaries with scanty colonies in the vicinity for Ampicillin, Penicillin G, Sulphatriad, Gentamicin, Cefepime and Co-trimoxazole discs.
The result of antibiogram study of past reports, had documented use of antibiotics like Gentamicin and Ciprofloxacin (Sharma et al., 2009), Levofloxacin (Pandey et al., 2018), Ceftriaxone (Manjhi et al., 2019), Ampicillin and Amoxycillin (Yadav and Jadhav, 2018) to be most efficacious and rated efficacy of tetracyclines in the range of 20 to $60 \%$. Dutt et al. (2017) reported that uterine infection associated microbes shows drug resistance against Oxytetracycline.

However, in this study, tetracycline appeared to be the most effective drug. This was in congruous with reports of Königsson et al. (2001) and Ingale et al. (2016). Few other studies have also reported intrauterine infusion of oxytetracycline to be most useful (Gohar et al., 2018; Manimaran et al., 2019) in treating uterine infections in bovines. The variations in the reports may be due to the involvement of diverse types of infectious agent. A set list of medications, may be difficult to be prescribed in uterine infection and antibiogram may be helpful in detecting and monitoring trends in antimicrobial resistance.

\section{Animals' response to the treatment}

In this study, the antimicrobial susceptibility was assessed individually and the cases were treated likewise, one-to-one. To the single case, where the infection was due to a yeast, the intra-uterine treatment was done by $0.05 \%$ povidoneiodine solution. 
On examination of cervical mucous in subsequent oestrus, the infection appeared to be considerably controlled in all the 35 animals. They exuded clear mucous (CM score=0), white-side test was negative and the per cent PMNs infiltration had reduced to 0 to $4 \%$. The animals were allowed to bred, and $57.14 \%$ (20 out of 35 ) were found to be pregnant when pregnancy was checked after 2.5 months following insemination. Rest, fifteen animals, which repeated again, were given Buserelin acetate (Receptal囚VET, $2.5 \mathrm{~mL}$ ) shot along with second Al. Out of fifteen, 5 had confirmed pregnancy while ten, remained to be repeat breeders following second Al. Thus, overall uterine infection associated RBS cases were effectively treated in $71.43 \%$ cases.

\section{CONCLUSION}

It can be concluded that the prompt diagnosis and efficient approach of therapeutics is of utmost importance for effective management of RBS cases associated with uterine infection. Owners should be made aware about uterine health importance in bovines, and the cases should be diagnosed only after thorough examination of cervical mucous during the period of oestrus. Confirmation should preferably include endometrial cytology, which is an easy to perform test. In western UP, Oxytetracyclin appeared to be the most effective antibiotic. However, as the resistance to antibiotics in the animals are found to be on individual basis, ideally antibiogram study should be done for rational and empirical treatment. Further, studies focusing on understanding regional differences in uterine infection epidemiology are necessary, particularly at field level, where there is currently a paucity of data. Routine investigation and monitoring studies need to be constantly conducted to update veterinary clinicians on the prevalent pathogens.

\section{ACKNOWLEDGEMENT}

This work was carried out by ICAR-CIRC, Meerut (Project No. OXX03793), with the support of the Farmer FIRST Project, ICAR-ATARI, Zone-IV, Kanpur funded by (Agril. Extn.), ICAR, KAB-1, Pusa, New Delhi. The authors are thankful to Director, ICAR-CIRC, Meerut for providing necessary facilities for conducting the study. Thanks are also due to Ashish Malik and Sandeep Kumar for their regular visits, feedback collection and tremendous liaising at field level.

\section{REFERENCES}

Asaduzzaman, K.M., Bhuiyan, M.M.U., Rahman, M.M. and Bhattacharjee, J. (2016). Prevalence of repeat breeding and its effective treatment in cows at selected areas of Bangladesh. Bangladesh Journal of Veterinary Medicine. 14: 183-190.

Bhat, F.A., Bhattacharyya, H.K. and Khan, M.Z. (2012). Studies on prevalence of repeat breeding in crossbred cattle of Kashmir valley. Indian Journal of Animal Research. 46: 306-309.
Bhat, F.A., Bhattacharyya, H.K. and Hussain, S.A. (2014). White side test: A simple and rapid test for evaluation of nonspecific bacterial genital infections of repeat breeding cattle. Veterinary research forum: An international quarterly Journal. 5(3): 177-180.

Dutt, R., Singh, G., Singh, M., Sharma, M., Dala, J. and Chandolia. (2017). Diagnosis of subclinical endometritis in murrah buffaloes through cytobrush technique. International Journal of Current Microbiology and Applied Sciences. 6(11): 494-499.

Gani, M.O., Amin, M., Alam, M.G.S., Kayesh, M.E.H., Karim, M.R., Samad, M.A. and Islam, M.R. (2008). Bacterial flora associated with repeat breeding and uterine infections in dairy cows. Bangladesh Journal of Veterinary Medicine. 6(1): 79-86.

Gilbert, R.O., Shin, S.T., Guard, C.L., Erb, H.N. and Frajblat, M. (2005). Prevalence of endometritis and its effects on reproductive performance of dairy cows. Theriogenology. 64: 1879-88.

Gohar, M.A., Elmetwallyl, M.A., Montaser, A. and Zaabel, S.M. (2018). Effect of Oxytetracycline treatment on postpartum reproductive performance in dairy buffalo-cows with retained placenta in Egypt. Journal of Veterinary Healthcare. 1(3): 45-53.

Heidari, M., Kafi, M. and Khodakaram-Tafti, A. (2016). Relationships between follicular fluid steroid concentrations and uterine infections in ovarian cystic cows. Comparative Clinical Pathology. 25: 865-870.

Ingale, A.M., Rai, R.B., Saminathan, M., Vadhana, P., Hingade, S.S., Dhama, K., Milton, A.A.P. and Singh, R. (2016). Isolation, PCR detection, pathotyping and antibiogram profiling of Escherichia coli associated with endometritis in buffaloes. Journal of Animal and Plant Sciences. 26(5): 1247-1254.

Königsson, K., Gustafsson, H., Gunnarsson, A. and Kindahl, H. (2001). Clinical and bacteriological aspects on the use of oxytetracycline and flunixin in primiparous cows with induced retained placenta and post-partalendometritis. Reproduction in Domestic Animals. 36(5): 247-256.

Kumar, H., Bhooshan, N., Dass, R.S. and Garg, A.K. (2013). Effect of treatment of immunomodulators on recovery and conception rate in endometritic buffaloes. Indian Journal of Animal Sciences. 83: 129-32.

Manimaran, A., Vishweswaraiah, R.H., Kumaresan, A., Sreela, L., Yadav, A., Layak, S.S., Mooventhan, P., Chand, S., Sarkar, S.N. and Sivaram, M. (2019). Oxytetracycline is more suitable antibiotic for clinical endometritis cows. The Indian Journal of Animal Sciences. 89(5): 501-505.

Manjhi, V.K., Bajaj, N.K., Shukla, S.P., Shrivastava, N., Kaurav, P.S. and Thakur, R.K. (2019). Bacterial isolation and antibiogram of uterine lavage from repeat breeder cows suffering from subclinical endometritis. Journal of Animal Research. 9: 293-296.

Noakes, D.E., Parkinson, T.J. and England, G.C.W. (2001). Arthur's Veterinary Reproduction and Obstetrics. $8^{\text {th }}$ edn. W.B. Saunders Company, England.

Pande, M., Das, G.K., Khan, F.A., Sarkar, M., Pathak, M.C., Prasad, J.K. and Kumar, H. (2013). Endometritis impairs luteal development function and nitric oxide and ascorbic acid concentrations in buffalo (Bubalusbubalis). Tropical Animal Health and Production. 45: 805-810. 
Pandey, N.K.J., Gupta, H.P., Prasad, S. and Sheetal, S.K. (2018). Therapeutic management of repeat breeding due to subclinical endometritis in crossbred cows. International Journal of Science, Environment and Technology. 7: 1868-1874.

Rangnekar, M.N., Bakshi, S.A., Deopurkar, V.L., Chinchkar, S.R., Birade, H.S., Gulvane, S.U., Hol, B.G. and Jadhav, P.D. (2005). Effect of enrofloxacin and metronidazole on pregnancy rate in repeat breeding cows. The Journal of Bombay Veterinary College. 13: 60-61.

Saini, P., Singh, M. and Kumar, P. (2019). Fungal endometritis in bovines. Open Veterinary Journal. 9: 94-98.

Saraswat, C.S. and Purohit, G.N. (2016). Repeat breeding: Incidence, risk factors and diagnosis in buffaloes. Asian Pacific Journal of Reproduction. 5: 87-95.

Sharma, S., Singh, S. and Vashisht, N.K. (2009). Isolation and antimicrobial susceptibility of aerobic bacteria recovered from the uteri of dairy cows suffering from endometritis. Indian Journal of Animal Sciences. 79 (3): 278-282.

Sheldon, I.M., Lewis, G.S., LeBlanc, S. and Gilbert, R.O. (2006). Defining postpartum uterine disease in cattle. Theriogenology. 65(8): 1516-30.

Singh, M., Sharma, A., Sharma, A. and Kumar, P. (2017). Repeat breeding and its treatment in dairy cattle of Himachal Pradesh (India) - A review. Indian Journal of Animal Reproduction. 38: 1-5.

Snedecor, G.W. and Cochran, W.G. (1994). Statistical Methods., $8^{\text {th }}$ edn. lowa State University Press, Ames.

Yadav, M.M. and Jadhav, S.S. (2018). Metritis Associated Aerobic Bacteria in Crossbred Dairy Cows and its Multiple Drug Resistance in Organized Dairy Farm, Maharashtra, India. International Journal of Current Microbiology and Applied Sciences. 7(12): 3629-3635. 